\title{
Nudge to better care - blood cultures and catheter-related bloodstream infections in Germany at two points in time $(2006,2015)$
}

\author{
Florian Salm ${ }^{1,2,3^{*}} \mathbb{D}$, Frank Schwab ${ }^{2,3}$, Michael Behnke 2,3 , Frank M. Brunkhorst ${ }^{4,5,6}$, André Scherag ${ }^{4,7}$ \\ Christine Geffers ${ }^{2,3}$ and Petra Gastmeier ${ }^{2,3}$
}

\begin{abstract}
Background: Blood cultures (BCs) are the gold standard for diagnosing sepsis and are prerequisite for a targeted antibiotic treatment and essential for patient outcomes. Aim of the study was to analyze the frequency of $\mathrm{BCs}$, the rate of central line-associated bloodstream infections (CLABSIs) and to study the association between both parameters on intensive care units in Germany over time.

Methods: Cross-sectional studies at two points in time $(2006,2015)$ on ICUs participating in the German hospital infection surveillance system. CLABSIs were defined according to the Center for Disease Control and Prevention (CDC). Univariable and multivariable analyses were performed using generalized linear models.

Results: A total of 639 ICUs participated in 2006 or 2015 and 90 ICUs ("core group") in both years. Overall, $2,427,921$ patient days from 644,575 patients were analyzed. In the ICU core group the frequency of BCs per 1000 patient days doubled from 57.8 (interquartile range [IQR] 29.8-101.2; 2006) to 128.2 (IQR 71.6-183.2; 2015). In the same time, the pooled median CLABSI rate decreased from 0.8 (IQR 0-1.9; 2006) per 1000 central-line catheter days to 0.2 (IQR 0-0.9; 2015).

Conclusions: From 2006 to 2015 the frequency of BCs increased on ICUs in Germany and is now within the recommended 100 to 200 BCs sets per 1000 patient days.
\end{abstract}

Keywords: Infection control, Bloodstream infections, Sepsis, Blood cultures, Surveillance, Healthcare associated infections

\section{Background}

Early and sufficient diagnostics to identify the causative pathogen is prerequisite for a timely therapy start, a targeted antibiotic treatment and most importantly for the patient outcome. It is essential to become aware of the pathogen and potential antibiotic resistances $[1,2]$. Sufficient diagnostic with $\mathrm{BC}$ can reduce mortality, length of stay on the intensive care unit and furthermore hospital expense [3, 4]. A targeted antimicrobial therapy can shorten the use of antibiotics and lower the selection pressure and the development of antibiotic resistances, it

\footnotetext{
* Correspondence: florian.salm@uniklinik-freiburg.de

${ }^{1}$ Institute for Infection Prevention and Hospital Epidemiology, Medical Center

- University of Freiburg, Faculty of Medicine, Freiburg, Germany

${ }^{2}$ Institute of Hygiene and Environmental Medicine, Charité -

Universitätsmedizin, Berlin, Germany

Full list of author information is available at the end of the article
}

is one of the core elements of antibiotic stewardship approaches [5]. A range of $100-200 \mathrm{BC}$ sets per 1000 patient days is recommended [6-8], especially because BSI detection rate depends on the frequency of the performance of BCs. Low performers have lower BSI rates compared to wards with a higher frequency in $\mathrm{BC}$ diagnostics $[8,9]$. Therefore, the frequency of BCs per ward is an important quality indicator if BSI rates are compared. Over the last decade there were a lot of approaches to improve patient safety in critically ill patients by reducing the prevalence of central line-associated bloodstream infections (CLABSIs) [10-13] and by increasing the frequency of performing BCs when there is a suspicion of a BSI [14-16].

The goal of this investigation was to evaluate the frequency of $\mathrm{BCs}$ and the influence on the detection rate of CLABSIs and the association between both

(c) The Author(s). 2018 Open Access This article is distributed under the terms of the Creative Commons Attribution 4.0 International License (http://creativecommons.org/licenses/by/4.0/), which permits unrestricted use, distribution, and reproduction in any medium, provided you give appropriate credit to the original author(s) and the source, provide a link to the Creative Commons license, and indicate if changes were made. The Creative Commons Public Domain Dedication waiver (http://creativecommons.org/publicdomain/zero/1.0/) applies to the data made available in this article, unless otherwise stated. 
parameters on ICUs in Germany at two points in the year 2006 and 2015 .

\section{Methods}

In Germany, the majority of acute care hospitals participate voluntary in the German hospital infection surveillance system (KISS, "Krankenhaus-Infektions-SurveillanceSystem") which is a surveillance system with confidential data feedback $[17,18]$. Data were included from ICUs participating in KISS. The surveillance in this module includes invariable different indicator infections like infections of the lower respiratory system (pneumonia and bronchitis), urinary tract infection and (laboratory-confirmed) BSIs. BSIs are defined according to the Center for Disease Control and Prevention (CDC) [19]. A BSI is central catheterassociated (CLABSI) when on the day with the first symptoms of the infection ("infection day") the patient had a catheter for at least 3 days. It must be mentioned, that the CDC definitions for CLABSI with coagulase-negative staphylococci (CNS) changed. Since 2011, at least two positive BCs with CNS are necessary to meet the criteria of a CNS-BSI. Before 2011, it was sufficient if at least one $\mathrm{BC}$ was positive with CNS and the attending physicians started an antimicrobial therapy. Therefore, all CLABSIs with $\mathrm{CNS}$ as a pathogen were excluded from the analysis. The CLABSI rate is calculated as the quotient of total BSI of patients with a central-line catheter divided by the total per 1000 central-line days (for more detail please see: nrz-hygiene.de). One BC is defined as a blood collection with no matter how many bottles but at least with one pair of aerobe und anaerobe $\mathrm{BC}$ bottles.

The German National Reference Center for Surveillance of Nosocomial Infections provides reference data for each healthcare-associated infection and works with social norm feedback. Mean, median and the 75th percentile are core parameters. Values within the upper quartile are highlighted. For selected infections and particular wards (e.g. neonatal intensive care units) a Standardized Infection Ratio (SIR) is provided and is calculated by the number of observed infections divided by the number of expected infections. The SIR is a parameter to help estimate whether the value is higher than in other wards with same characteristics. In addition, the data are graphically processed as a distribution curve and as funnel plots. Outlier values are also highlighted in the graphical representation.

2006 and 2015 a cross-sectional survey among the KISS participants was carried out to collect the blood culture density (BCD). BCD is defined as frequency of BCs per 1000 patient days per ICU. The method of the cross-sectional study conducted in the year 2006, is described in detail elsewhere [9]. Ten years later, in 2015, a cross-sectional study was carried out using the same methods as in the first investigation. Within the participants from $2006(n=223)$ and $2015(n=506)$, 90 ICUs provided data in both years and will be called core-group in the following.

\section{Statistical analysis}

In the descriptive analysis we calculate pooled mean, median and interquartile range (IQR) in total and stratified by year, type of hospital and hospital size ( $</>600$ beds), type of ICU, the device use, the invasive ventilation rate and length of stay. Differences between categories were tested by Chi-squared test. The rates of the years 2006 and 2015 in the core-group were tested by Wilcoxon test for paired samples and in the entire cohort by WilcoxonMann-Whitney test for unpaired samples.

To investigate the association between the incidences of CLABSI and the frequency of $\mathrm{BC}$ univariable and multivariable analysis were performed using generalized linear models (GLM). In the models, we used negativebinomial distribution as probability distribution and the logarithm of central venous catheter (CVC) days was treated as offset parameter. To adjust for confounding the following variables were considered in the regression analysis: type and size of hospital, type and size of ICU, device use of $\mathrm{CVC}$, ventilation and urinary tract catheter and length of stay. In the univariable analyses incidence rate ratios (IRR) were calculated for the individual factors. In the multivariable analyses, adjusted IRRs for BC density categories were calculated and all variables with $p<0.1$ in the univariable analyses were included following a stepwise backward variable selection (excluding a variable from the model if $p>0.05$ in the type III test).

All analyses were performed using SPSS [IBM SPSS statistics, version 23, Somer, NY, USA] and SAS 9.4 [SAS Institute, Cary, NC, USA].

\section{Ethical approval}

All data were anonymous and collected in accordance with the German recommendation for good epidemiological practice with respect to data protection [20]. As a federal law, the German Protection against Infection Act ("Infektionsschutzgesetz" \$23) regulates the prevention and management of infectious diseases in humans. All hospitals are obliged to continuously collect and analyse healthcare-associated infections and drug-resistant pathogens [21]. These data are reported regularly to the National Reference Centre for the Surveillance of nosocomial infections. Ethical approval and informed consent were therefore not required.

\section{Results}

A total of 639 ICUs participated in 2006 or 2015 and 90 ICUs in both years. Overall, 2,427,921 patient days from 644,575 patients were analyzed. Over 1352 CLABSIs with no CNS as pathogen and 343,388 BCs were reported. 
Wards characteristics can be seen in Table 1. In the ICU core group the BCD doubled from 57.8 (interquartile range [IQR] 29.8-101.2; 2006) to 128.2 (IQR 71.6-183.2; 2015, see Fig. 1a). In the same time, the pooled median CLABSI rate decreased from 0.8 (IQR 0-1.9; 2006) per 1000 central-line catheter days to 0.2 (IQR 0-0.9; 2015, see Table 1 and Fig. 1b). The crude and adjusted incidence rate ratios for the BCD categories compared to 50-99 BC per 1000 patient days can be found in Table 2 and Fig. 2. Wards with 100-199 BC per 1000 patient days did not detect significantly more CLABSIs compared to those wards with $50-99 \mathrm{BC}$ per 1000 patient days. ICUs with more than 250 BCs per 1000 patient days had a 1.50 (95\% confidence interval [CI] 1.07-2.11) higher risk to detect CLABSIs compared to ICUs with a low frequency of BCs (5099- BCs per 1000 patient days). The adjusted IRR for the outcome CLABSI increased with higher frequency of BCs, length of stay and decreased significantly comparing the years 2006 and 2015 (IRR 0.74, 95\%CI 0.60-0.92).

\section{Discussion}

We conducted 2006 and 2015 cross-sectional surveys on, in total, 639 intensive care units in Germany. We found an increase in the frequency of BCs and a significant decrease of catheter-related primary bloodstream infections. An important question is what has caused the strong increase in the $\mathrm{BC}$ performance?

In 2007, the German DRG- (Diagnosis Related Groups) reimbursement system changed and for sepsis, a new diagnosis code (R.65) was implemented. It became mandatory to perform at minimum two sets of $\mathrm{BCs}$

Table 1 Intensive care units (ICU) characteristics - data from all ICUs $\left(n=639^{* *}\right)$ and from the core group $(n=90)$ from two time points year 2006 and year 2015

\begin{tabular}{|c|c|c|c|c|c|c|}
\hline \multirow[t]{2}{*}{ Characteristics/ Outcomes } & \multicolumn{2}{|c|}{ Total ICUs $\left(n=639^{* *}\right)$} & \multicolumn{2}{|c|}{ Core Group $(n=90)$} & \multicolumn{2}{|l|}{ Core group $(n=90)$} \\
\hline & $2006(n=223)$ & $2015(n=506)$ & $2006(n=90)$ & $2015(n=90)$ & Diff. 2015-2006 & $p$-value \\
\hline \multicolumn{7}{|l|}{ Size of ICU } \\
\hline ICU beds, median (IQR) & $11(8-14)$ & $12(9-16)$ & $11(9-14)$ & $11(9-14)$ & - & - \\
\hline ICU > =12 beds, N (\%) & $100(44.8)$ & $285(56.3)$ & $50(55.6)$ & $50(55.6)$ & & \\
\hline \multicolumn{7}{|l|}{ Type of ICU, N (\%) } \\
\hline Surgical & $40(17.9)$ & $77(15.2)$ & $15(16.7)$ & $15(16.7)$ & & \\
\hline Interdisciplinary & $108(48.4)$ & $285(56.3)$ & $41(45.6)$ & $41(45.6)$ & & \\
\hline Medical & $47(21.1)$ & $73(14.4)$ & $21(23.2)$ & $21(23.2)$ & & \\
\hline Neurosurgical & $4(1.8)$ & $9(1.8)$ & $2(2.2)$ & $2(2.2)$ & & \\
\hline Neurological & $4(1.8)$ & $11(2.2)$ & $2(2.2)$ & $2(2.2)$ & & \\
\hline Pediatric & $7(3.1)$ & $9(1.8)$ & $3(3.3)$ & $3(3.3)$ & & \\
\hline other $^{a}$ & $13(5.8)$ & $42(8.3)$ & $6(6.7)$ & $6(6.7)$ & & \\
\hline \multicolumn{7}{|l|}{ Size of hospital } \\
\hline Hospital beds, median (IQR & $490(274-841)$ & $431(270-724)$ & $511(289-890)$ & $511(289-890)$ & - & - \\
\hline Hospital > = 600 beds, N (\%) & $85(38.5)$ & $174(34.4)$ & $36(40.0)$ & $36(40.0)$ & & \\
\hline \multicolumn{7}{|l|}{ Type of hospital } \\
\hline Tertiary hospital, N (\%) & $67(30.0)$ & $130(25.7)$ & $41(45.6)$ & $41(45.6)$ & & \\
\hline Patients, median (IQR) & $741(506-1036)$ & $814.5(492-1191)$ & $763.5(489-1053)$ & $722(434-1112)$ & - & - \\
\hline Patient days, median (IQR) & $2744(1854-3643)$ & $3245(2183-4365)$ & $2744(1915-3624)$ & $3028(2153-4215)$ & - & - \\
\hline CLABSI rate ${ }^{c}$, median (IQR) & $0.6(0.0-1.3)$ & $0.5(0.0-1.2)$ & $0.8(0-1.9)$ & $0.2(0-0.9)$ & $-0.01(-1.14-0.02)$ & 0.001 \\
\hline Blood culture density ${ }^{\mathrm{a}}$, median (IQR) & $60.0(32.6-107.9)$ & $115.4(67.6-177.4)$ & $57.8(29.8-101.2)$ & $128.2(71.6-183.2)$ & $54.8(1.6-119.1)$ & 0.001 \\
\hline Length of stay, median (IQR) & $3.6(2.7-5.2)$ & $3.8(3-5.5)$ & $3.6(2.8-5.5)$ & $4.2(2.9-6.2)$ & $0.3(-0.5-1.3)$ & 0.025 \\
\hline CVC use ${ }^{b}$, median (IQR) & $67.3(49.5-82.1)$ & $66.6(52.9-80.4)$ & $70.8(54.2-83.7)$ & $69.0(57.7-82.7)$ & $0.6(-6.3-8)$ & 0.672 \\
\hline Invasive ventilation use ${ }^{\mathrm{b}}$, median (IQR) & $34.1(22.7-49.9)$ & $36.8(26.1-50.4)$ & $35.3(21.9-52.0)$ & $37.1(26.5-55.6)$ & $3.1(-6.4-10.3)$ & 0.078 \\
\hline $\begin{array}{l}\text { Urinary tract catheters use }{ }^{b} \text {, } \\
\text { median (IQR) }\end{array}$ & $81.3(70.5-91.5)$ & 85.4 (75.5-92.0) & $83.7(71.6-93.0)$ & 86.7 (78.2-92.4) & $2.5(-2.8-10.0)$ & 0.003 \\
\hline
\end{tabular}

Abbreviations: Diff difference, IQR interquartile range, CVC central venous catheter, CLABSI central-line-associated bloodstream infection

"Wilcoxon-rank-sum test for paired sample; ${ }^{* *} 90$ ICUs collected data in 2006 and 2015

aper 1000 patient days

ber 100 patient days

cper 1000 CVC-days 

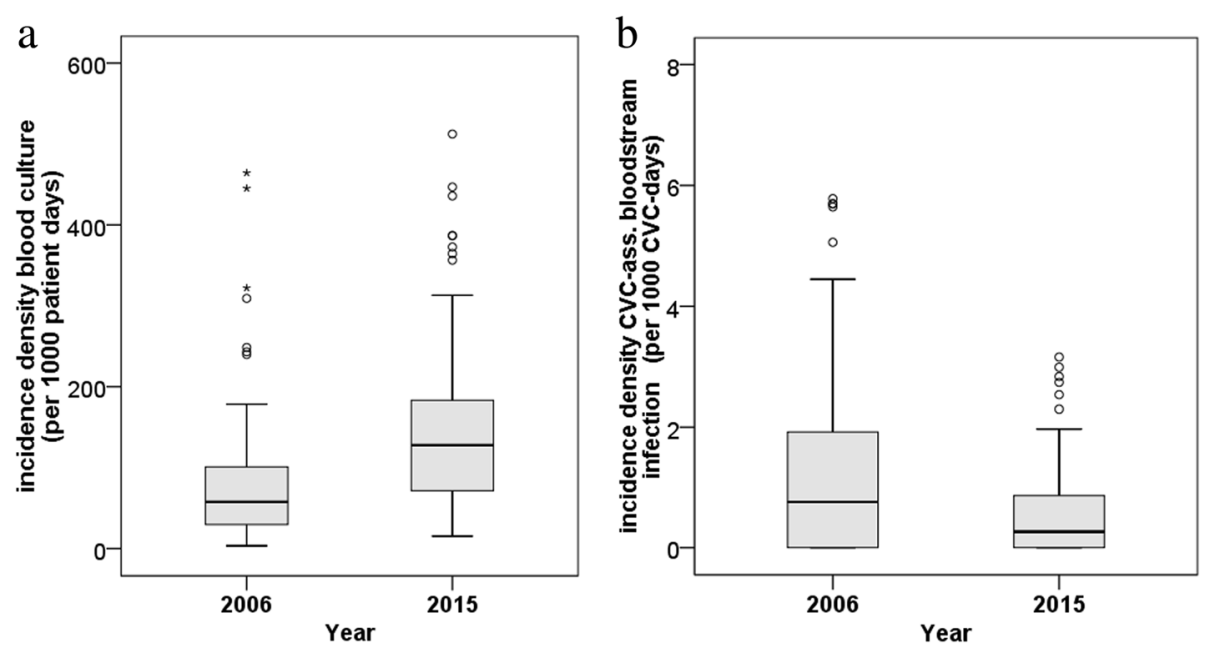

Fig. 1 a Incidence densitiy of blood cultures in the core group $(n=90)$, b Incidence densitiy of central line-associated bloodstream infection in the core group $(n=90)$

Table 2 Results from the univariable and multivariable regressions analysis using generalized linear models ${ }^{\mathrm{a}}$ with the outcome central line-associated bloodstream infection

\begin{tabular}{|c|c|c|c|c|c|c|c|}
\hline \multirow[t]{2}{*}{ Parameter } & \multirow[b]{2}{*}{ Category /unit } & \multicolumn{3}{|c|}{ Univariable Analysis } & \multicolumn{3}{|c|}{ Multivariable Analysis } \\
\hline & & $\overline{\mathrm{IRR}}$ & $95 \% \mathrm{Cl}$ & $p$-value & $\overline{\mathrm{IRR}}$ & $95 \% \mathrm{Cl}$ & $p$-value \\
\hline \multirow[t]{6}{*}{ blood culture density (per 1000pd) } & $<50$ & 1.07 & $0.81-1.41$ & 0.639 & 1.00 & $0.76-1.32$ & 0.996 \\
\hline & $100-149$ & 1.07 & $0.81-1.4$ & 0.637 & 1.14 & $0.87-1.50$ & 0.343 \\
\hline & 150-199 & 1.18 & $0.87-1.6$ & 0.283 & 1.26 & $0.93-1.71$ & 0.139 \\
\hline & $200-249$ & 1.38 & $0.91-2.09$ & 0.127 & 1.48 & $0.98-2.23$ & 0.061 \\
\hline & $>=250$ & 1.46 & $1.04-2.05$ & 0.029 & 1.50 & $1.07-2.11$ & 0.019 \\
\hline & $50-99$ & \multicolumn{3}{|l|}{$1=$ reference } & \multicolumn{3}{|l|}{$1=$ reference } \\
\hline Length of stay (days) & per day & 1.05 & $1.02-1.08$ & 0.001 & 1.05 & $1.02-1.08$ & 0.001 \\
\hline Year (compared to year 2006) & 2015 & 0.83 & $0.68-1.02$ & 0.079 & 0.74 & $0.60-0.92$ & 0.006 \\
\hline Invasive ventilation use (per 100 pd) & per $1 \%$ & 1.01 & $1-1.01$ & 0.004 & & & \\
\hline CVC use (per 100 pd) & per $1 \%$ & 1 & $0.99-1$ & 0.143 & & & \\
\hline Urinary tract catheter use (per 100 pd) & per $1 \%$ & 0.99 & $0.99-1$ & 0.013 & & & \\
\hline \multirow[t]{7}{*}{ type of ICU } & medical & 1.49 & $1.15-1.94$ & 0.002 & & & \\
\hline & surgical & 1.17 & $0.9-1.51$ & 0.239 & & & \\
\hline & neurosurgical & 1.27 & $0.62-2.61$ & 0.514 & & & \\
\hline & neurological & 1.26 & $0.61-2.57$ & 0.534 & & & \\
\hline & pediatric & 1.27 & $0.6-2.66$ & 0.533 & & & \\
\hline & other ${ }^{a}$ & 1.81 & $1.27-2.58$ & 0.001 & & & \\
\hline & interdisciplinary & $1=$ reference & & & & & \\
\hline Size of ICU & $>12$ beds & 1.11 & $0.91-1.34$ & 0.306 & & & \\
\hline type of hospital & tertiary & 1.59 & $1.24-2.03$ & $<.001$ & & & \\
\hline size of hospital & $>600$ beds & 1.37 & $1.13-1.65$ & 0.001 & & & \\
\hline
\end{tabular}

IRR incidence rate ratio, $C l$ confidence interval, $p d$ patient days, CVC central venous catheter, ICU intensive care unit

${ }^{a}$ The generalized linear models (GLM) with the outcome CLABSI and negative-binomial distribution as probability distribution and the logarithm of CVC days as offset parameter analyzed 729 yearly observations from 639 different ICUs in the years 2006 and 2015 


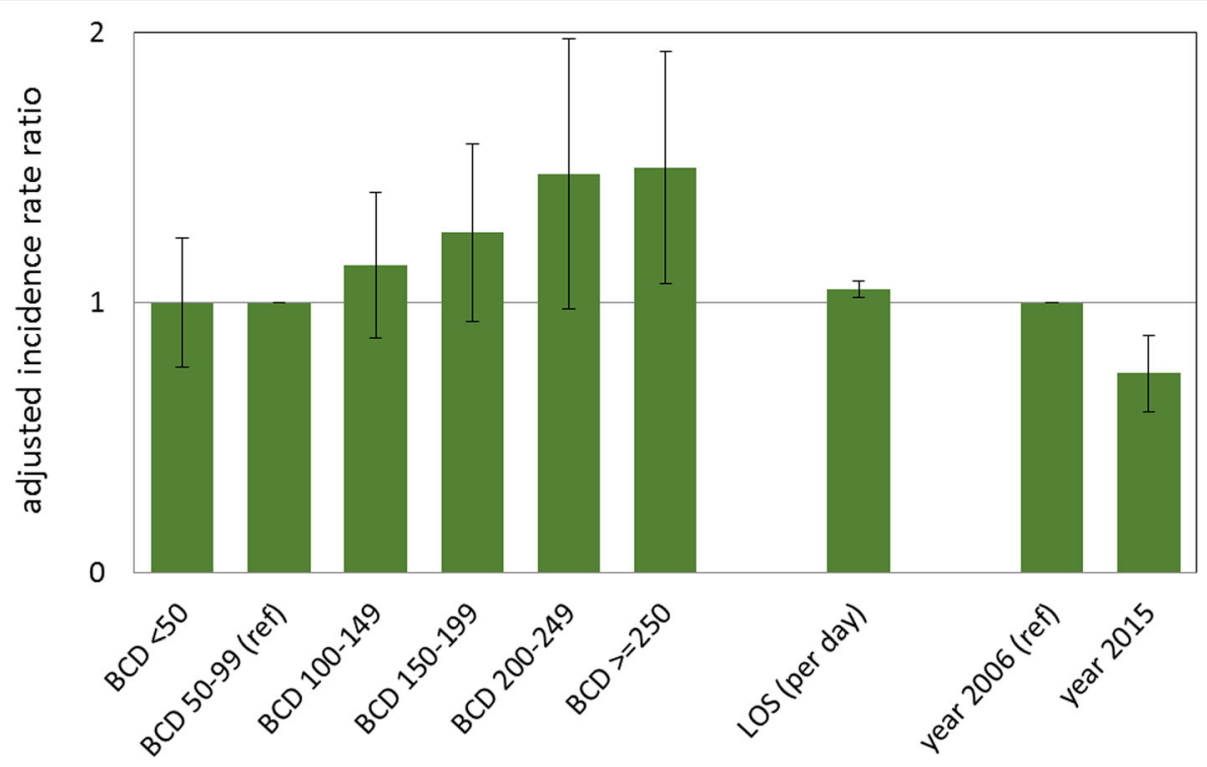

Fig. 2 Adjusted incidence rate ratios for blood culture density categories with the outcome central line-associated bloodstream infection (per 1000 CVC days), results of the multivariable regression analysis of 639 wards, 2006 \& 2015. Whiskers represent 95\% confidence interval. BCD, blood culture density per 1000 patient days; ref., reference in the model; LOS, length of stay

for the reimbursement of a R.65 patient case [22]. It can be assumed that the change in the DRG-reimbursement system influenced the BCD. Furthermore, several projects addressed this issue over the last years and tried to increase guideline adherence and the implementation of evidence-based diagnostic standard in the care of patients with suspicion of a bloodstream infections $[15,23]$. It is well described that higher frequency of BCs are associated with a higher detection rate of BSIs $[8,9]$. After a linear trend between culturing rates and the detection of BSIs with higher frequency of $\mathrm{BCs}$ a saturation effect can be found, but the optimal frequency of BCs is not well described yet [24]. Focusing on used DRG codes (R.65) for sepsis and sepsis shock, the clinical correlates of BSI, the annual number rose significantly between 2007 to 2013 [25]. In contrast, the CLABSI rate decreased enormously from 2006 to 2015. Potentially, the CLABSI rate decreased due to the different infection and control measures to improve patient safety in critically ill patients by implementing intervention bundles focusing on proper insertion techniques and managing of the CVCs over the last decade [10-13]. In the United States there are approaches to reduce preventable health-care associated infections with Pay for Performance policy [26, 27]. Some authors emphasize that reduced payments for CLABSIS did not influence the overall CLABSI rate [27]. On the other hand, from 2008 to 2014 the rate of CLABSIs decreased about $50 \%$ in the United States [28], while the BC rate declined from 2008 to 2010 [26]. Calderwood and colleagues highlighted that after implementation of the Pay for Performance policy the CLABSI rates decreased in hospitals operating at a financial loss, but in those operating at a financial profit the CLABSI rate was not affected by the policy [29]. In summary, the impact of the Pay for Perfomance system on the CLABSI rate in the United States is still unclear.

Nevertheless, considering that in Germany we found a similar decrease in the CLABSI rate without reimbursement penalties, we must critically scrutinize Pay for Performance approaches, especially when the outcome can be influenced by diagnostic methods.

However, the burden of health-care associated bloodstream infection is very high with estimated 160.000 cases and a number of about 25.000 attributable deaths in Europe per year [30]. Some investigations pointed out that German inpatient care physicians still have deficits concerning the knowledge of $\mathrm{BC}$ sampling; however, the results of this study suggest a positive upward trend in the frequency of BC sampling [31, 32]. Raupach-Rosin et al. reported that the majority of the physicians do not adhere to diagnostic guideline recommendations (two sets of BC from two different sites) [31].

The results are limited by the point that the 1976 reported BSI occurred after the 3rd day according to the surveillance protocol and are only primary BSIs. In contrast, the 343,388 reported BCs are from 1st day until discharge. It must be also considered that the median length of stay on the ICU per patient was less than 4 days. In this investigation, it remains unclear how many $\mathrm{BCs}$ were done due to primary and how many due to secondary BSI diagnosis. Nevertheless, from 2006 to 2015 the BCD increased enormously on ICUs and is 
now within the recommended range for $\mathrm{BC}$ of 100 to $200 \mathrm{BCs}$ sets per 1000 patient days [6]. While the large number of observed ICUs $(n=639)$ with over two million patient days under surveillance is a strength of this study, the temporal comparison was limited to the core group of 90 ICUs. However, this core group had consistent ward characteristics over the 10 -year period.

\section{Conclusion}

In conclusion, we must assume that many of the BC diagnostics are associated with secondary BSIs. Despite the expected parallel increase of BSI rates a decrease of primary BSI was observed. This underlines our observations of a decreasing trend of BSI rates in ICUs participating in the German hospital infection surveillance system [17].

\section{Abbreviations}

BC: Blood culture; BCD: Blood culture density; BSI: Bloodstream infection; CLABSI: Central line-associated bloodstream infection; CNS: Coagulasenegative; CVC: Central venous catheter; GLM: Generalized linear models; ICU: Intensive care unit; IQR: Interquartile range; IRR: Incidence rate ratios; SIR: Standardized infection ratio

\section{Acknowledgements}

Not applicable.

\section{Funding}

The study was not funded.

\section{Availability of data and materials}

The datasets used and/or analyzed during the current study are available from the corresponding author on reasonable request.

\section{Authors' contributions}

FSa, CG and PG led initial study design and development. MB, FSC and PG led the data collection. FSC and FSa led the analysis with input from FMB and AS, who also helped to draft the manuscript. All authors have made essential contributions to the interpretation of the data and to the preparation of the manuscript. All authors approved the final version of the manuscript.

\section{Ethics approval and consent to participate}

Not applicable, because all data were surveillance based data which were obtained within the German Law on Protection against Infection ("Infektionsschutzgesetz").

\section{Consent for publication}

Not applicable, because all data were surveillance based data which were obtained within the German Law on Protection against Infection ("Infektionsschutzgesetz").

\section{Competing interests}

The authors declare that they have no competing interests.

\section{Publisher's Note}

Springer Nature remains neutral with regard to jurisdictional claims in published maps and institutional affiliations.

\section{Author details}

${ }^{1}$ Institute for Infection Prevention and Hospital Epidemiology, Medical Center - University of Freiburg, Faculty of Medicine, Freiburg, Germany. ${ }^{2}$ Institute of Hygiene and Environmental Medicine, Charité - Universitätsmedizin, Berlin, Germany. ${ }^{3}$ National Reference Center for the Surveillance of Nosocomial Infections, Berlin, Germany. ${ }^{4}$ Center for Sepsis Control and Care, Jena University Hospital, Jena, Germany. ${ }^{5}$ Center for Clinical Studies, Jena University Hospital, Jena, Germany. ${ }^{6}$ Department of Anesthesiology and Intensive Care Medicine, Jena University Hospital, Jena, Germany. 'Institute of
Medical Statistics, Computer Sciences and Documentation, Jena University Hospital, Jena, Germany.

Received: 14 June 2018 Accepted: 8 November 2018

Published online: 21 November 2018

\section{References}

1. Liu VX, Fielding-Singh V, Greene JD, Baker JM, Iwashyna TJ, Bhattacharya J, et al. The timing of early antibiotics and hospital mortality in Sepsis. Am J Respir Crit Care Med. 2017;196:856-63.

2. Singer M, Deutschman CS, Seymour CW, Shankar-Hari M, Annane D, Bauer $M$, et al. The third international consensus definitions for Sepsis and septic shock (Sepsis-3). JAMA. 2016;315:801-10.

3. Berild D, Mohseni A, Diep LM, Jensenius M, Ringertz SH. Adjustment of antibiotic treatment according to the results of blood cultures leads to decreased antibiotic use and costs. J Antimicrob Chemother. 2006; 57:326-30.

4. Adrie C, Garrouste-Orgeas M, Ibn Essaied W, Schwebel C, Darmon M, Mourvillier B, et al. Attributable mortality of ICU-acquired bloodstream infections: impact of the source, causative micro-organism, resistance profile and antimicrobial therapy. J Inf Secur. 2017;74:131-41.

5. Barlam TF, Cosgrove SE, Abbo LM, MacDougall C, Schuetz AN, Septimus EJ, et al. Implementing an antibiotic stewardship program: guidelines by the Infectious Diseases Society of America and the Society for Healthcare Epidemiology of America. Clin Infect Dis Off Publ Infect Dis Soc Am. 2016:62:e51-77.

6. Seifert H, Abele-Horn M, Fätkenheuer G, Glück T, Jansen B, Kern WV, et al. Blutkulturdiagnostik: sepsis, endokarditis, katheterinfektionen. DGHM DGfHuM Ed Mikrobiol-Infekt Qual MiQ Elsevier. 2007:74-5.

7. Baron EJ, Weinstein MP, Dunne WM Jr, Yagupsky P, Welch DF, Wilson DM Cumitech 1C, blood cultures IV, p 1-16, 23-25 coordinating ed, baron EJ, editor. Washington, DC: ASM Press; 2005.

8. Karch A, Castell S, Schwab F, Geffers C, Bongartz H, Brunkhorst FM, et al. Proposing an empirically justified reference threshold for blood culture sampling rates in intensive care units. J Clin Microbiol. 2015;53:648-52.

9. Gastmeier P, Schwab F, Behnke M, Geffers C. Less blood culture samples: less infections? Anästhesist. 2011;60:902-7.

10. Gavin NC, Webster J, Chan RJ, Rickard CM. Frequency of dressing changes for central venous access devices on catheter-related infections. Cochrane Database Syst Rev. 2016;2:CD009213.

11. Lai NM, Lai NA, O'Riordan E, Chaiyakunapruk N, Taylor JE, Tan K. Skin antisepsis for reducing central venous catheter-related infections. Cochrane Database Syst Rev. 2016;7:CD010140.

12. Sutcliffe KM, Paine L, Pronovost PJ. Re-examining high reliability: actively organising for safety. BMJ Qual Saf. 2017;26:248-51.

13. Pronovost $P$, Needham D, Berenholtz S, Sinopoli D, Chu H, Cosgrove S, et al An intervention to decrease catheter-related bloodstream infections in the ICU. N Engl J Med. 2006:355:2725-32.

14. Karch A, Schmitz RP, Rißner F, Castell S, Töpel S, Jakob M, et al. Bloodstream infections, antibiotic resistance and the practice of blood culture sampling in Germany: study design of a Thuringia-wide prospective population-based study (AlertsNet). BMJ Open. 2015;5:e009095.

15. Weis S, Hagel S, Schmitz RPH, Scherag A, Brunkhorst FM, Forstner C, et al. Study on the utility of a statewide counselling programme for improving mortality outcomes of patients with Staphylococcus aureus bacteraemia in Thuringia (SUPPORT): a study protocol of a cluster-randomised crossover trial. BMJ Open. 2017;7:e013976.

16. Schmitz RP, Keller PM, Baier M, Hagel S, Pletz MW, Brunkhorst FM. Quality of blood culture testing-a survey in intensive care units and microbiological laboratories across four European countries. Crit Care. 2013;17:R248.

17. Schröder C, Schwab F, Behnke M, Breier A-C, Maechler F, Piening B, et al. Epidemiology of healthcare associated infections in Germany: nearly 20 years of surveillance. Int J Med Microbiol. 2015;305:799-806.

18. German hospital infection surveillance system > KISS (KrankenhausInfektions-Surveillance-System). [cited 2017 May 22]. Available from: nrzhygiene.de/surveillance/kiss/

19. Horan TC, Andrus M, Dudeck MA. CDC/NHSN surveillance definition of health care-associated infection and criteria for specific types of infections in the acute care setting. Am J Infect Control. 2008;36:309-32.

20. Deutsche Gesellschaft für Epidemiologie. Leitlinien und Empfehlungen zur Sicherung von Guter Epidemiologischer Praxis (GEP). 2004. BMBF 
Gesundheitsforschung URL https://dgepi.de/assets/Leitlinien-und-Empfe hlungen/6074a4e7b8/Leitlinien-fuer-Gute-Empidemiologische-Praxis.pdf. Accessed 24 Jan 2017. WebCite Cache ID 6nlBtZZZO. 2016.

21. Gesetz zur Verhuetung und Bekaempfung von Infektionskrankheiten beim Menschen (Infektionsschutzgesetz - IfSG). 2017. BGBI. I S. 2615. Available from: https://www.gesetze-im-internet.de/ifsg/

22. Brunkhorst FM, Seifert $H$, Kaasch A, Welte T. Leitliniengerechte Blutkulturdiagnostik bei Sepsis und schweren Organinfektionen in der Intensivmedizin-ein unterschätztes Defizit. Dtsch Ärzte-Verl. 2010:1-8.

23. Scheer CS, Fuchs C, Kuhn S-O, Vollmer M, Rehberg S, Friesecke S, et al. Quality improvement initiative for severe Sepsis and septic shock reduces 90-day mortality: a 7.5-year observational study. Crit Care Med. 2017;45:241-52.

24. Laupland KB, Niven DJ, Pasquill K, Parfitt EC, Steele L. Culturing rate and the surveillance of bloodstream infections: a population-based assessment. Clin Microbiol Infect. 2018:24:910.e1-4.

25. Fleischmann C, Thomas-Rueddel DO, Hartmann M, Hartog CS, Welte T, Heublein S, et al. Hospital incidence and mortality rates of Sepsis. Dtsch Arzteblatt Int. 2016;113:159-66.

26. Kadri S, Hohmann S, Zhang F, O'Grady N, Klompas M. 24: impact of penalties for central line-associated bloodstream infections on blood culture ordering. Crit Care Med. 2016;44:92 Available from: https://journals.Iww.com/ ccmjournal/Fulltext/2016/12001/24__IMPACT_OF_PENALTIES_FOR_ CENTRAL.27.aspx.

27. Lee GM, Kleinman K, Soumerai SB, Tse A, Cole D, Fridkin SK, et al. Effect of nonpayment for preventable infections in U.S. hospitals. N Engl J Med. 2012; 367:1428-37.

28. Centers for Disease Control and Prevention. Current HAI Progress Report 2016 National and State Healthcare-Associated Infections Progress Report. Atlanta: CDC. p. 2016. Available from: https://www.cdc.gov/hai/progressreport/index.html

29. Calderwood MS, Vaz LE, Kawai AT, Jin R, Rett MD, Grant PS, et al. Impact of hospital operating margin on central line-associated bloodstream infections following Medicare's hospital-acquired conditions payment policy. Infect Control Hosp Epidemiol. 2016;37:100-3.

30. Cassini A, Plachouras D, Eckmanns T, Abu Sin M, Blank H-P, Ducomble T, et al. Burden of six healthcare-associated infections on European population health: estimating incidence-based disability-adjusted life years through a population prevalence-based modelling study. PLoS Med. 2016;13:e1002150.

31. Raupach-Rosin H, Duddeck A, Gehrlich M, Helmke C, Huebner J, Pletz MW, et al. Deficits in knowledge, attitude, and practice towards blood culture sampling: results of a nationwide mixed-methods study among inpatient care physicians in Germany. Infection. 2017;45:433-41.

32. She RC, Alrabaa S, Lee SH, Norvell M, Wilson A, Petti CA. Survey of physicians' perspectives and knowledge about diagnostic tests for bloodstream infections. PLoS One. 2015;10:e0121493.

Ready to submit your research? Choose BMC and benefit from:

- fast, convenient online submission

- thorough peer review by experienced researchers in your field

- rapid publication on acceptance

- support for research data, including large and complex data types

- gold Open Access which fosters wider collaboration and increased citations

- maximum visibility for your research: over $100 \mathrm{M}$ website views per year

At $\mathrm{BMC}$, research is always in progress.

Learn more biomedcentral.com/submissions 